\title{
Los laberintos del viajero De San Gimignano a las torres Mullieris de Puerto Madero
}

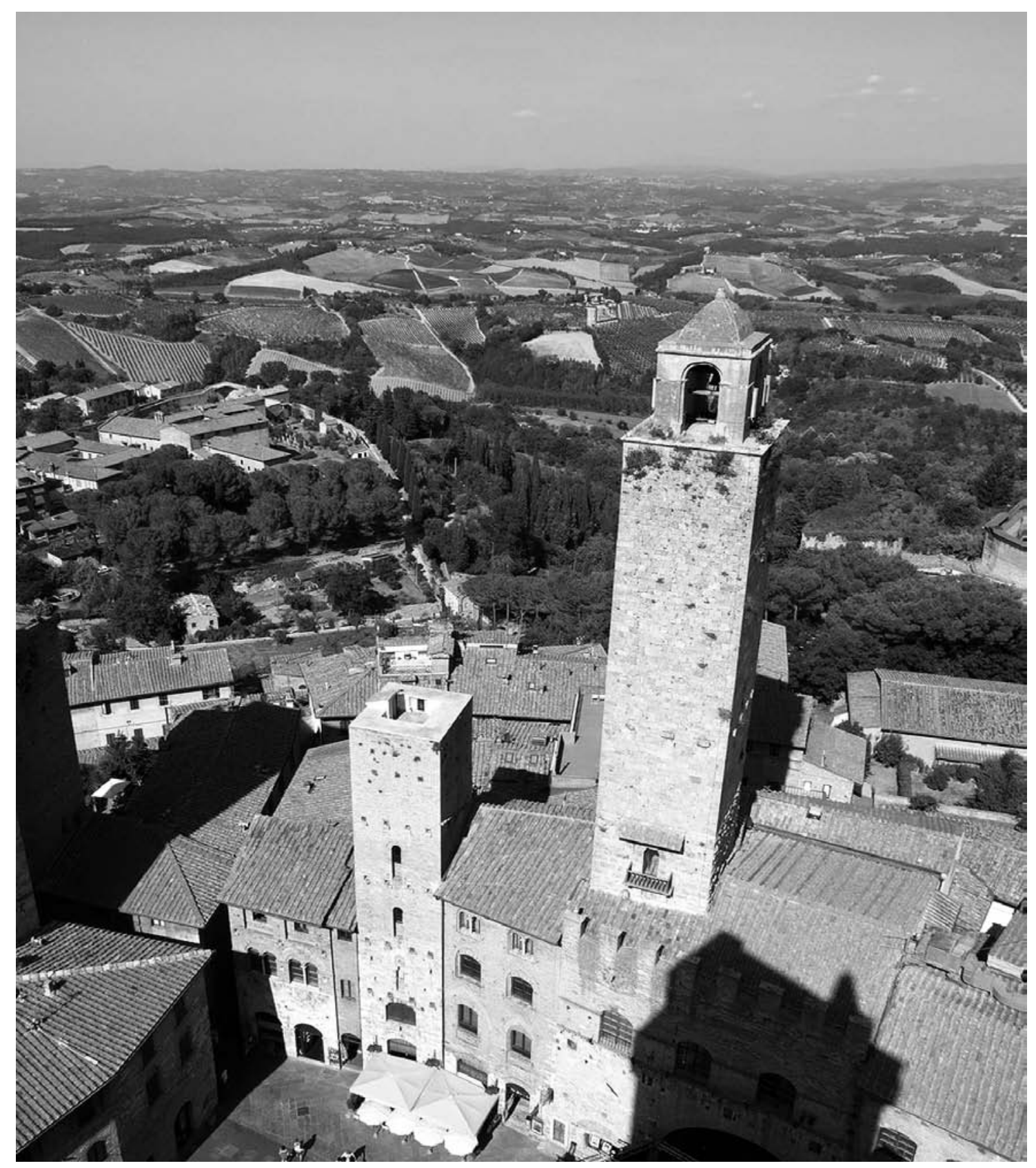

Torres de San Gimignano, región Toscana, Italia. 


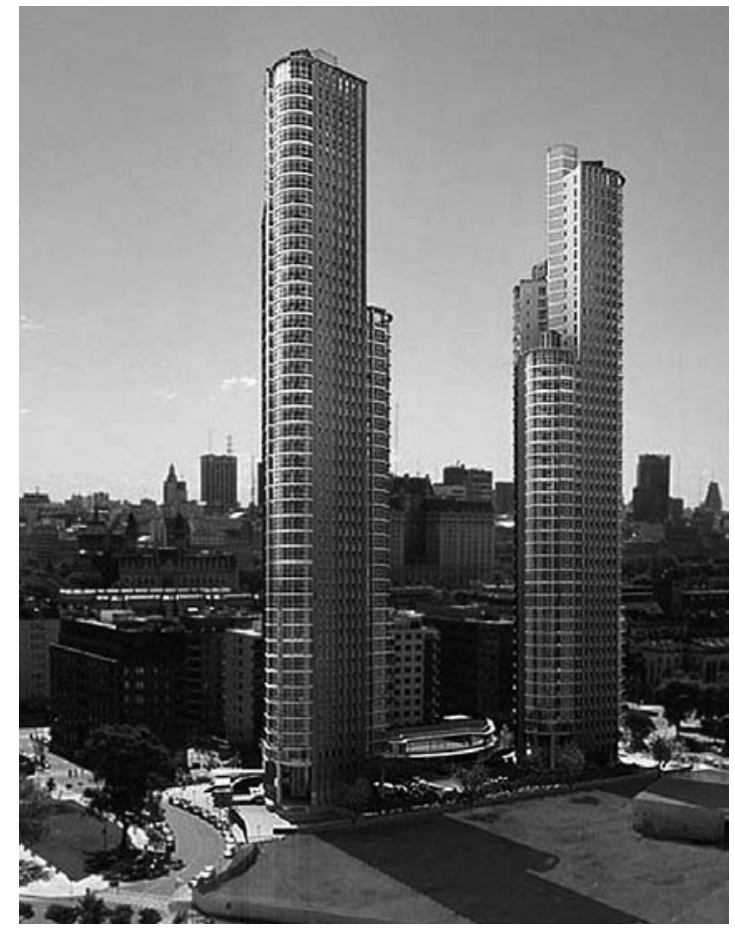

Torres Mullieris, Puerto Madero, Buenos Aires.

Sin ser uno de esos arquitectos que viajan y realizan croquis de los edificios que ven, y con esa mirada y elaboración propia a través del dibujo nos enseñan a aprender proporciones, escalas, relaciones urbanas, como muy bien lo ha demostrado el Corbu en su viaje de juventud a Grecia y Roma; aún sin incluirme en esa forma de viajar debo reconocer que ha habido ocasiones en los cuales ciertos viajes me han motivado a compartir mis apreciaciones acerca de la arquitectura con mis alumnos y docentes. Así, conversamos sobre ciertas paradojas entre Cuba y Las Vegas; o la extraña perduración del posmodern en Estados Unidos cuando se daba por concluido en Europa; o descubrir en una New York, que visito poco, cuánto valen nuestros referentes modernos. ${ }^{1} Y$ en efecto esas relaciones son transmisibles porque nos permiten construir nuevas preguntas; pero al mismo tiempo son también subjetivas porque aquellas puertas que se abren mentalmente al viajar por la sóla distancia de aquello que nos preocupa habitualmente nos desplaza del centro y nos da otras posibilidades de pensar o pensarse a sí mismo desde lejos.

Entonces algunas reflexiones acerca de la arquitectura muy reciente en algunos sitios lejanos entre sí me gustaría compartir: en el año 2007 viajé a España e Italia; luego, por razones laborales, estuve en Beijing; y entre uno y otro viaje estuvimos en las ciudades de Mar del Plata y Santa Fe con la exposición del estudio. Acompañado por una cámara fotográfica digital, que hoy me provee de las imágenes de esta nota, voy registrando aquello que seguramente se relaciona con alguna situación de Buenos Aires, o de la Argentina que se puede comparar para bien o para mal; aún con los riesgos de las comparaciones espontáneas o alejado de los libros de historia; o de una historia que aún no se ha escrito como la referida a la arquitectura de nuestro país de los últimos años.

En ese sentido es que uno de mis viajes alentó aquella visión optimista que tuve de la crisis del 2001, cuando decía que por un largo tiempo los jóvenes dejarían de recibir las revistas como El Croquis y podrían comenzar a pensar con referentes más cercanos, que pudieran construirse con tecnología disponible y que ellos mismos verificaran la calidad de los edificios construidos ${ }^{2}$. En efecto, el primer viaje a España, antes de llegar a Italia, me preocupó ver el mal estado de edificios muy recientes y muy difundidos por las revistas europeas. El primero de ellos es el edificio triangular de gran escala en Barcelona, proyectado por los arquitectos suizos...

Así me resultó un gran alivio encontrarme con la buena arquitectura italiana del quatrocento; y casi más aún el bellísimo pueblo de San Gimignano con esas torres que emergieron como disputa entre Guelfos y Gibelinos, esas dos familias que edificaron cerca de 72 torres (de las cuales perduran catorce), y son un magnífico ejemplo de composición entre la trama urbana medieval, que se continúa con el quatrocento en esos edificios homogéneos de planta baja, plano novile y un desarrollo de tres o cuatro pisos más y conforman un paisaje homogéneo 1-2 $_{2}$ Cfr: Solsona, J. (2007):

que se abre a espacios públicos como la fonte gaia o la Hacer ydecir. Ediciones Infinito, Piazza del Campo; ejemplos que nosotros no tenemos en 


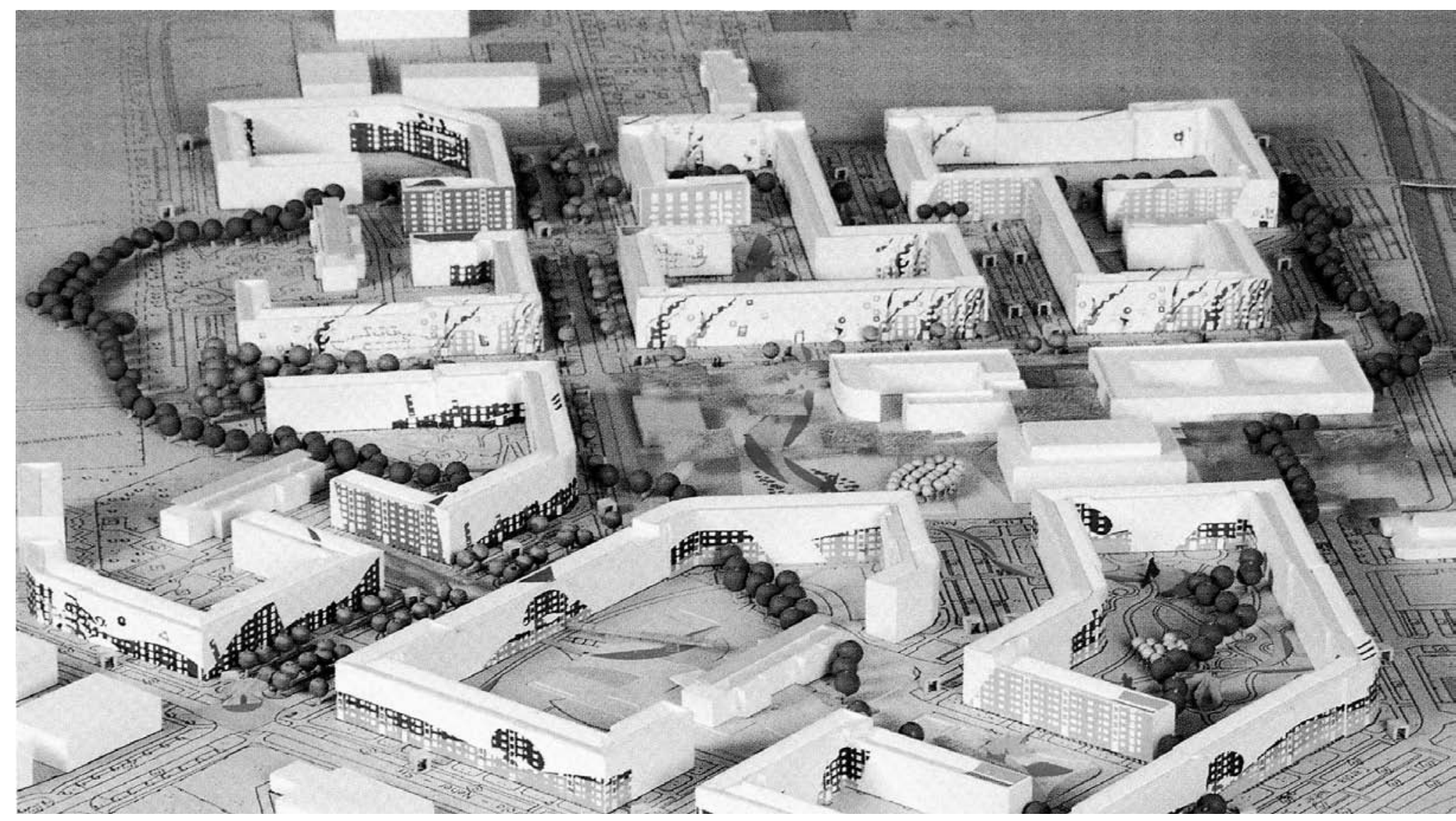

Tony Díaz: conjunto de viviendas en Alcorcón, España.

nuestra historia. Y esas torres, que cumplían con su función de miradores, efectivamente tienen unas vistas hacia la campiña toscana maravillosa; pero lo más impactante es la austeridad de su materialidad, la escala que compone en la ciudad y las proporciones en sí mismas. Un poblado que, casi azarosamente, al girar desde una callejuela, o desde el espacio abierto del paisaje toscano uno encuentra la imagen esbelta y bien proporcionada de alguna de sus torres.

$Y$ con diferencia de apenas dos meses me encontré en la ciudad de Beijing, donde hoy se celebran los juegos olímpicos. Y allí vi, casi desalentado, cómo los estudios muy profesionalizados toman encargos de gran magnitud y desarrollan sus edificios como un catálogo de lo moderno que incorpora sus materiales pero no se realiza el trabajo minucioso del diseño, ni se estudian las proporciones, ni el paisaje urbano que van configuran- do sino que, por el contrario, se construye masivamente, como una sumatoria de volúmenes y fachadas de vidrio que no están muy bien.

En cambio, recientemente he visitado el conjunto de viviendas en Alcorcón de Tony Díaz en España que me permite un sinnúmero de reflexiones acerca de la arquitectura de interés social, sus referentes, materialidad y normativas estéticas y, por supuesto, preguntarnos acerca de la deuda más importante que tenemos los arquitectos e instituciones públicas en la Argentina respecto de la vivienda masiva. En efecto, esta nueva obra de Díaz es un gran contrapunto en referencia a todo lo dicho anteriormente: si los europeos más divulgados se dedican a una arquitectura sin límites o sujeta a los límites que les impone las posibilidades de la tecnología y se define por la gestualidad que demanda los máximos recursos para ser construida; el esfuerzo de Tony Díaz se focaliza en 


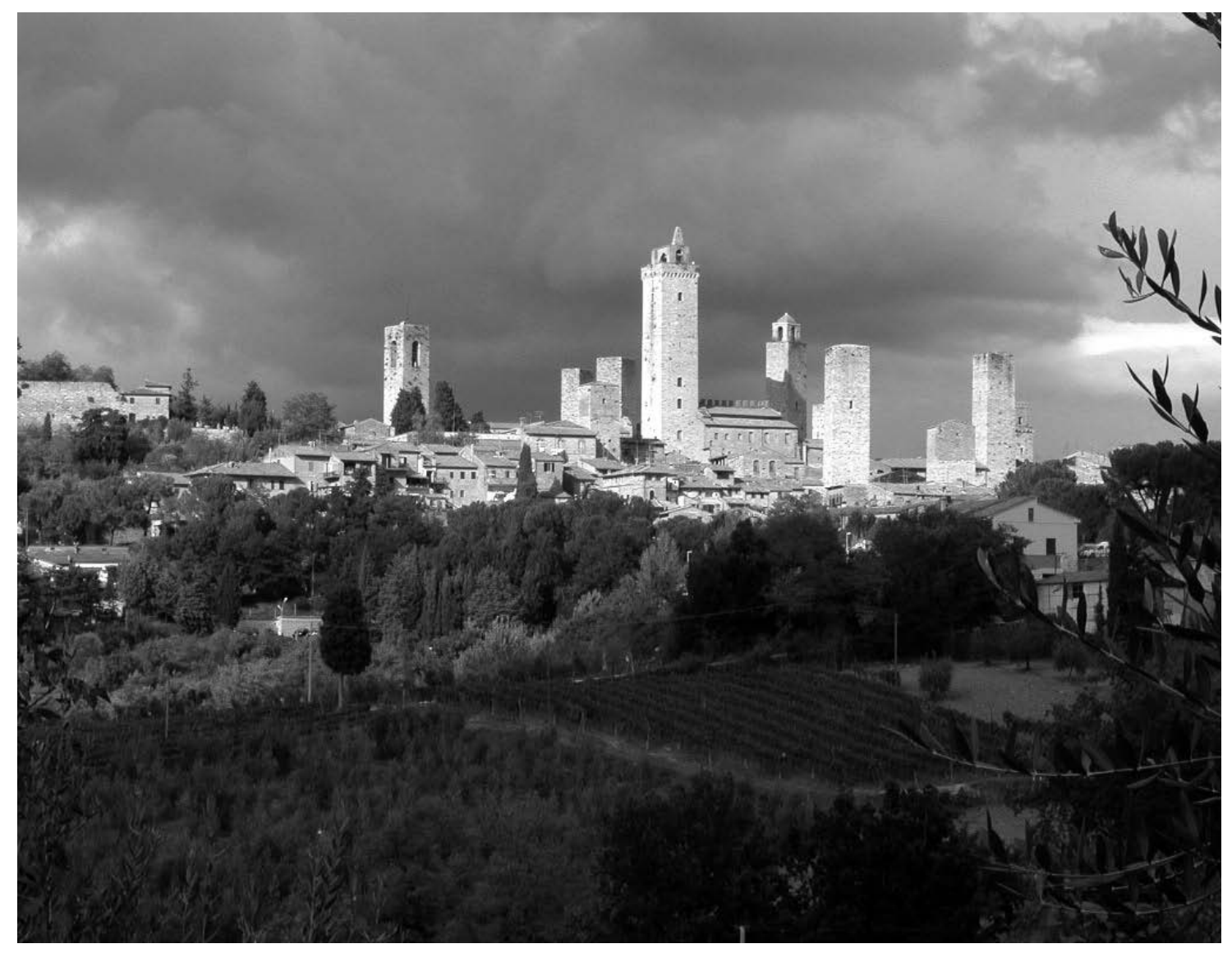

Torres en el paisaje de la Toscana.

cómo producir con lo mínimo: un personaje ascético que intenta operar con lo esencial en la búsqueda de una arquitectura que brinde nuevas respuestas a un viejo problema: la vivienda social.

Así, las tres intervenciones que realiza en la ciudad son conjuntos que se insertan en un plan urbano previsto por el Estado, con normativas que difieren de las nuestras pero que concibe la manzana urbana, donde se concentra una serie de intervenciones mínimas que socavan la creencia en esos gestos grandilocuentes, artísticos, tan de moda. Las suyas son simples intervenciones del cuadrado.

Y en su trabajo de reelaboración tan personal o solitario, Díaz le da continuidad a un proceso ya iniciado ante el cual se pregunta qué hay que rescatar de la experiencia; qué nos sirve y qué no de las distintas variantes de los modernismos y sus segundas lecturas. Así, un conjunto de herramientas como las barras, las ventanas, las puertas, la manzana, el patio, están allí como un repertorio que se piensa a sí mismo; no son un límite sino la potencialidad de reforzar, con la profundidad de la insistencia, la confianza intelectual en las ideas con las cuales resiste los discursos y presiones del medio. Así intenta construir su nuevo discurso que se define por su austeridad formal e introduce como novedad el color, que quizá podemos relacionar con los barrios de La Boca o Lanin en Barracas; y así sus habitantes disponen de sus fachadas con sus propios criterios. Es una apertura, una paleta posible.

Y el color es efectivamente una preocupación que tiene sus precedentes en la arquitectura que se desarrolla en los barrios de las ciudades europeas más importantes, como una variante a los modernismos más reivindicativos de las primeras vanguardias con las que se va re- 
construyendo Europa después de la primera guerra. En efecto, a fines de los años noventa, Clorindo Testa y yo participamos en un concurso de renovación de viviendas en la ciudad de Berlín y el primer premio lo obtuvo un arquitecto brasileño que desplegaba su alegría en coloridas fachadas como un contrapunto al tono gris, permanente de aquellas latitudes.

Como me ocurre al ver la obra de Chesterfield y sus edificios para la Ciudad Judicial en Barcelona, los suyos son gestos mínimos, uno al observarlos intuye que algo sucede, casi imperceptible pero nos obliga a detenernos para pensar qué es; vas descubriendo la idea del arquitecto que hay por detrás pero a través de la reflexión: casi casi, si no fuera por la angustia, se parece al secreto de la novela policial, una sospecha siempre al filo de ser develada por la inteligencia. En cambio, los gestos grandilocuentes, efectistas, espectaculares, cuyo paradigma es, a mi entender, la arquitectura de Frank Ghery (que no estoy ni siquiera dispuesto a visitar), impacta visualmente en un momento; y no hay mucho más para pensar.

Pero no nos distraigamos de un tema que debe ser nuestro: la ciudad moderna que crece con la vivienda masiva. Porque Alcorcón, al prescindir de la gran altura, nos interroga acerca de nuestra experiencia en la vivienda y quisiera referirme entonces a la tipología de la torre, que considero un tema de esencial discusión dentro de la arquitectura como un problema de la cultura urbana. La torre, como tema de arquitectura encuentra cierta tradición donde confluye lo constructivo y la proporción en ejemplos como San Gimignano; donde convive con las alturas homogéneas y más bajas que producen cualidades y recintos urbanos de gran belleza. En cambio, la tipología de la torre es una propuesta del siglo XX que acompaña las expectativas de la modernidad al desarroIlar la ciudad con la solución de la vivienda masiva. Es en ese sentido que nuestro estudio se inicia en el tema con el concurso público para resolver el conjunto de viviendas del barrio de La Boca en 1957, que por razones políticas y económicas quedó interrumpido en la etapa de documentación. Una década después, desarrollamos el Conjunto Rioja como una tipología con una propuesta urbana que recupera el nivel cero para la ciudad y constituye una vivienda de clase media que hoy se encuentra en excelente estado de mantenimiento. Ya avanzados los setenta participamos en los últimos emprendimientos del estado para resolver la vivienda de escasos re- cursos en forma masiva y la tipología de la torre se integra a otras tipologías de distintas alturas en el conjunto Piedrabuena. Hoy, en cambio, y desde los noventa, esta tipología es un tema casi excluyente del mercado que decide invertir y desarrollar emprendimientos orientados a la clase media (cuando había sistema de créditos), o viviendas de alto poder adquisitivo como Alto Palermo y las Mullieris, actualmente en obra.

Desde esta variada experiencia (que los críticos e historiadores se ocupan de estudiar y evaluar ${ }^{3}$ ), y creyendo que la ciudad es la gran obra de la modernidad en la his- 3 Nota Foro y Anahí Ballent. toria de la cultura occidental es que creo en la gran esca- 4 Exposición 1930-1950 Arquitectura la urbana producto de la alta densidad de habitantes. $\quad \begin{array}{ll}\text { moderna en la ciudad de Buenos Aires. } \\ \text { CP67, Buenos Aires. Reedición 2005. }\end{array}$ Lamentablemente, la injerencia del Estado como interlocutor en obras importantes para la ciudad ha desaparecido y tal vez se esté recuperando (si es cierto que la cantidad de concursos fallados en años muy recientes se construyen), pero lo cierto es que en el tema de la vivienda de bajos recursos se vuelve a los programas de unidades unifamiliares de planta baja y un piso que expanden sin límites el subdesarrollo en las zonas de provincias que no disponen de servicios públicos. En cambio, ¡debemos celebrar que la gente quiera vivir en las ciudades! Cuánta más gente viva en condiciones urbanas más cultura tendremos; cuánta más gente tenga que verse entre sí, mejor estaremos; estoy seguro, estaremos mejor. La soledad de estar aislado no ha sido nunca un aporte a la civilización: la civilización se construye a partir de las ciudades y me opongo firmemente a ese abandono de la ciudad hacia los countries como si fuesen ghetos de la felicidad.

Prepararnos para aquello que vendrá implica que debemos reconocer y valorizar como parte de nuestro patrimonio aquella arquitectura de los años treinta y cuarenta que consolidó Buenos Aires y constituye un referente para la ciudad que crece en altura. Con los alumnos de la Facultad de Arquitectura entre 1984 y 1987 realizamos una exposición sobre los edificios del Racionalismo ${ }^{4}$, que también habíamos trabajado en la Escuelita durante la dictadura; intentando con ello construir un referente cultural y profesional a la vez: esa buena arquitectura es el resultado de la confluencia entre la ética de resolver la vivienda masiva y la estética que las nuevas formas del hormigón armado nos permitían descubrir. Pero Buenos Aires recibe un golpe duro, que quizá haya sido imperceptible aún para nosotros, cuando el código de edifica- 


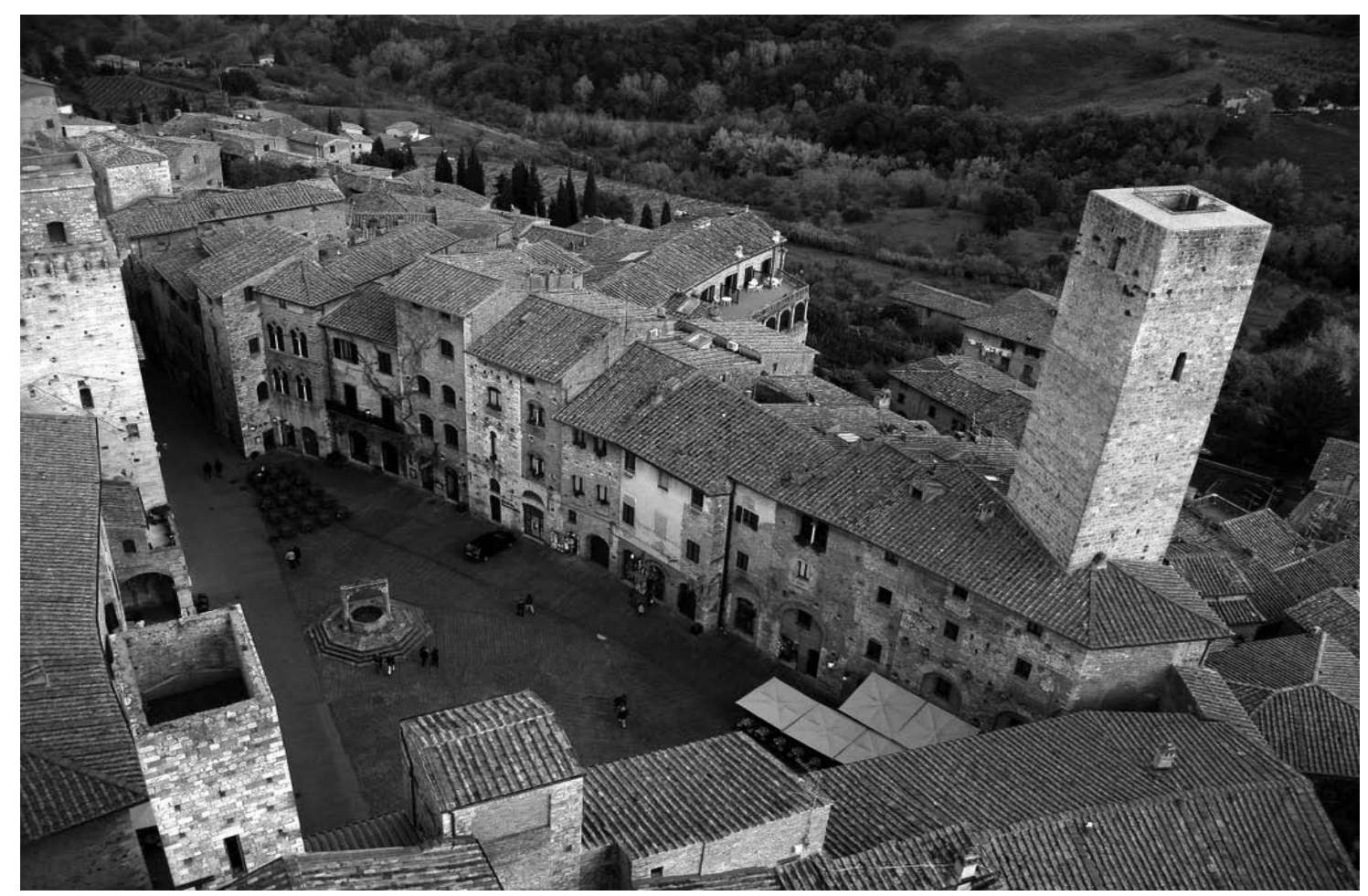

Piazza Cisterna.

ción que proviene de las normativas de los edificios de renta se modifica y los tres metros de altura libre entre pisos se restringen a dos metros sesenta centímetros según la ley de propiedad horizontal (1945). Esa pérdida de masa entre uno y otro piso, que permitía jugar con las bandas horizontales de llenos y vacíos, ha llevado a pensar a los edificios en altura como meras sumatorias de pisos mil hojas y los vacíos en anodinos balcones que frecuentemente ni siquiera tienen las dimensiones necesarias para el uso adecuado de una expansión en los tropicales veranos porteños.

Es evidente que ese cambio de código está vinculado a la rentabilidad del suelo; pero a nosotros lo que nos importa es la pérdida de las bellas proporciones de esas fachadas blancas y austeras que definió cualitativamente la transformación urbana.

Entonces, como arquitecto y profesor, debo decir que estamos frente a un tema de la cultura de la arquitectura sin resolver y que requiere más discusión y pensamiento porque la construcción en altura es el futuro. Si se hará bien o se hará mal es nuestra responsabilidad y la de los gobiernos. Insisto en que la ciudad debería tener un comité evaluador o un equipo de expertos autárquico que siga de cerca la resolución de un anteproyecto para torres y su elaboración no concluya fácilmente en ¡cuatro meses! Porque las torres, como tipología no pueden ubicarse en cualquier lugar de la ciudad. Cuando las torres se agrupan y forman entre sí un paisaje propio como sucede en Buenos Aires en la zona de Puerto Madero, constituye un fragmento urbano con cualidades distintas a la trama homogénea habitual.

Si la torre está bien trabajada como lenguaje, como una pieza urbana de cien o ciento cincuenta metros, su escala equivale a un puente y comienza a transformar las ciudades, como sucede en Londres con la obra de Foster; esto no quiere decir que a mí me guste su obra, pero debo reconocer que una nueva arquitectura se está construyendo en el mundo; va tomando posición ante dos fenómenos que crecen desmesuradamente: la pobreza y la necesidad de lugares para vivir. 